\title{
Development of Firm in Conditions of Heterogeneity of Goods and Producers
}

\author{
Ismagilova G. N. ${ }^{1}$, Gafurov I. R. ${ }^{1} \&$ Safiullin N. Z. ${ }^{1}$ \\ ${ }^{1}$ Institute of Management, Economics and Finance, Kazan Federal University, Kazan, Russia \\ Correspondence: Ismagilova G. N., Kazan Federal University, Institute of Management, Economics and Finance, \\ Kazan, 420008, Russia.
}

Received: March 10, 2015 Accepted: March 31, 2015 Online Published: April 30, 2015

doi:10.5539/ass.v11n11p264 URL: http://dx.doi.org/10.5539/ass.v11n11p264

\begin{abstract}
The article presents new results of research in the field of the theory of firm. It introduces multidimensional additive and nonlinear models of interrelation of the supply and its factors. It studies the supply factors connected with qualitative and quantitative characteristics of this economic category. Interconnection and functional dependences of the supply on many factors are established, including are defined supply volume from quality, the price and competitiveness of goods, and also from the major production factors. The law of supply in space of the price - quality-competitiveness is introduced. The set of diagrams and examples is given.
\end{abstract}

Keywords: theory of firm, goods, producers, complimentary goods, substitute goods

\section{Introduction}

The analysis of the size (volume) of the supply in known works begins with its qualitative party.

As with demand, a desire or even ability to produce the product and deliver it to the market is not enough. The supply arises only when this economic subject is ready to make the transaction on sale of these goods delivered on the market. Respectively, the volume of the supply will be defined by the maximum quantity of the goods prepared for sale for this period of time under existing conditions. And the volume of the supply is the stream proceeding in time. Therefore it is necessary to connect it with the period of time to which it belongs. Thus, the volume of the supply is the amount of that product or service which the seller offers to sell at a specific price within a specific period of time.

\section{Data and Methodology}

In work where supply volume is most in detail stated, the following factors of the supply are given: price of these goods $p^{s}=\left(p_{1}^{s}, p_{2}^{s}, \ldots, p_{n}^{s}\right)$, price of substitute goods $p^{c}=\left(p_{1}^{c}, p_{2}^{c}, \ldots, p_{m}^{c}\right)$, prices of complimentary goods, costs of production $\mathrm{y}_{\mathrm{T}}$, taxes and subsidies $\left(\mathrm{z}_{\mathrm{T}}\right)$, objective, external conditions of production $\left(\mathrm{x}_{\mathrm{T}}\right)$, expectations of producers $\left(\mathrm{e}_{\mathrm{T}}\right)$ of the product.

Built with consideration of these factors, the supply function describes the dependence of the volume of supply from these factors:

$$
Q^{s}=f\left(p, p^{s}, p^{c}, x_{T}, y_{T}, z_{T}, e_{T}\right)
$$

This function of demand has a number of shortcomings.

First, it doesn't consider such important factors as quality of these goods, quality of goods substitutes (interchangeable goods), quality of the complementary benefits (complementary goods) and their competitiveness.

At the same time quality is a main factor of competitiveness as quality by definition is set of properties and characteristics of goods or other object which gives it ability to satisfy the caused or estimated requirements. Also we will note that supply - quantity and a variety of the goods offered for satisfaction of demand grows with growth of the price, increasing in connection with demand of "hungry elite", almost boundless on a variety and quality (see chapter 3). It sets the tone for the supply, initiates it and excites. However if totally the size of the supply grows, the supply size increment as functions of the price falls, aspiring to some limit size. It is natural as it is impossible to offer more than that "the hungry elite" and all society in general can ask. 
The supply strives for balance with demand, at the growing price for all population and regardless of the price for "elite" of society. It seems illogical. However, in reality that is exactly what happens as increase of the price of goods during time goes with saturation (not only in connection with decrease of limit usefulness of goods), coming nearer to some limit determined by balance supply - demand. The closer supply and demand approach equality, the higher the ceiling of the price is and the more slowly the price grows. This reached ceiling of the prices, of supply and demand is maintained only by "elite", but supported by other part of the population asking and offering goods.

The part of production necessary for satisfaction of the minimum physiological needs of the person is characterized by nondecreasing limit usefulness. Producers of the goods forming the supply always have a desire to reduce the volume of release of this production demand on which almost doesn't depend on the price which therefore incurs them losses. This production is produced mainly under pressure of the laws imposed by the state and in limited volume, usually do it in the form of patronage.

Another large part of industrial production has declining marginal utility. This is all the products which are produced for the satisfaction of needs, above the minimum, to meet the desires and demands of fashion, prestige, and demand for luxury.

Besides, known expression of the supply describes only that circumstance that the volume of the supply depends on the specified determinants. However the type of this function (4.1) in well-known works isn't opened and isn't specified how this function can be constructed taking into account a number of factors.

In this direction only dependence of volume of the supply on one factor - on the price is in detail considered at the assumption of constancy of all other factors.

However wide use of concept of supply necessary for disclosure of market mechanisms is connected with establishment of interrelation of supply with all these factors, including also quality of these goods, quality of interchangeable and complementary goods and competitiveness of these goods.

This circumstance is important when developing methodology of the analysis of supply and ensuring competitiveness of economic objects and subjects. Determinants of supply are the factors determining supply size. They, as well as demand determinants, are subdivided into two big groups: price and non-price.

The price of these goods, the price of goods substitutes (interchangeable resources), the prices of the complementary goods (complementary resources), costs of production, taxes and subsidies belong to price factors.

Conditions of production, expectations of consumers belong to non-price factors objective, external (first of all, natural). In our opinion, quality of these goods, quality of goods substitutes, quality of the complementary benefits and competitiveness of the transferred goods considerably makes impact on supply volume.

- Their interaction on supply volume in well-known works isn't considered. Therefore we consider quality of these goods, quality of interchangeable goods and quality of complementary goods and their competitiveness as supply determinants.

- Further in a material statement we will use the following designations of factors of supply:

- $\quad$ price (p), quality ( $\mathrm{g}$ ) and competitiveness ( $\mathrm{\kappa}$ ) of the given good;

- $\quad$ price $p^{s}=\left(p_{1}^{s}, p_{2}^{s}, \ldots, p_{n}^{s}\right)$, quality $g^{s}=\left(g_{1}^{s}, g_{2}^{s}, \ldots, g_{n}^{s}\right)$ and competitiveness $k^{s}=\left(k_{1}^{s}, k_{2}^{s}, \ldots, k_{n}^{s}\right) \quad$,of interchangeable goods;

- $\quad$ price $p^{c}=\left(p_{1}^{c}, p_{2}^{c}, \ldots, p_{m}^{c}\right)$, quality $g^{c}=\left(g_{1}^{c}, g_{2}^{c}, \ldots, g_{m}^{c}\right)$ and competitiveness $k^{c}=\left(k_{1}^{c}, k_{2}^{c}, \ldots, k_{m}^{c}\right) \quad$ of complementary goods;

- the cost of production of goods $\left(\mathrm{y}_{\mathrm{T}}\right)$, covering both the technology of production, determining the necessary amount of resources used, and the prices of these resources

- $\quad$ taxes and subsidies $\left(\mathrm{z}_{\mathrm{T}}\right)$;

- objective, external (first of all, natural) conditions of production $\left(\mathrm{x}_{\mathrm{T}}\right)$;

- $\quad$ expectations of producers $\left(\mathrm{e}_{\mathrm{T}}\right)$.

The supply function constructed taking into account these influences will characterize dependence of volume of supply on these factors:

$$
Q^{s}=f\left(p, g, k, p^{s}, g^{s}, k^{s}, p^{c}, g^{c}, k^{c}, x_{T}, y_{T}, z_{T}, e_{T}\right)
$$


therefore the expression of function of supply introduced by us (4.2.) is more general in comparison with the known expression (4.1) depending on limited number of factors.

As follows from expression (4.2), the volume of supply depends on the following factors: price and quality of these goods, price and quality of each goods substitute, price and quality of the complementary goods, competitiveness of these goods, costs of production, taxes and subsidies, objective and external conditions of production, expectation of consumers.

Among these factors of supply there are both the independent, and interconnected factors. For example, objective and external conditions of production, obviously, don't depend on costs of production as they are defined by a condition of environment and are uncontrollable. When building the model of supply the look and the direction of interrelation of factors of supply have certain values.

\section{Results (Obligatory)}

Taking into account economic conditions of the market the volume of supply can be considered depending on change of each factor separately and from change of several factors at the same time. In this regard we will introduce the following concepts. Function of the factorial supply is a dependence of quantity of goods on the changing its factor for this period at constancy of other factors. Function of the factorial supply can be considered concerning change of one or several factors. Then we deal with the one-factorial and two-factorial supply or supplies depending on three and more factors. Respectively the number (volume) of supply will be defined by the maximum quantity of the goods prepared for sale for this period of time depending on change of several factors. The factorial supply characterizes readiness of the manufacturing seller to sell a certain quantity of these or those goods depending on change of one or several factors during a certain period of time.

The type of function of supply (4.2) depending on all these factors isn't known currently. Apparently, such function of supply from influence of all these specified factors is absent. Creation of such general view of function of supply is interfaced to difficult models of factorial supplies, taking into account the direction of influence of each factor on the total volume of supply, etc. The factorial supply can be considered as reaction of manufacturing sellers to influence of any factor separately or two and more factors at the same time. On the basis of an induction method we can present supply volume in the form of the sum of responses of producers to influence of all factors of supply and their combinations. In this regard, the properties and characteristics of producers-sellers, transformative impact factors in the reaction in some cases may be subject to superposition principle. In this case function of supply from these listed factors is linear. Then function of supply will represent the algebraic sum of all components of the factorial supplies defined as reaction of manufacturing sellers to each factor in separateness.

However properties and characteristics of manufacturing sellers not always submits to the principle of superposition. Then function of supply from these factors will be strictly nonlinear. Obviously, in this case the exit from the created situation caused by nonlinearity of characteristics of manufacturing sellers also can be found. Thus responses of characteristics, i.e. factorial supplies, can be added with their combinational components of responses which will reflect nonlinear properties of characteristics of manufacturing sellers on influence of factors of supply of goods. Combinational components of volume of supply is nothing but a part of result of simultaneous influence of two or more factors.

In well-known references the general view of such full total volume of supply is absent. Below we offer one most effective methodology of designing of function of supply taking into account properties of factors of supply.

Additive models of supply. A more complete "picture" of supply, in comparison with the known, can be obtained based on the use of additive models. The additive model of supply in space of many factors, reflects more complete market situation than Marshall's model of supply which considers supply depending on one factor - the prices at constancy of "other conditions", the additive model reflects influence of each factor that weakens influence on supply volume of "other conditions".

Like it was shown, "other conditions" aren't constant, they change according to change of a factor of the price, and influence, therefore, points of balance turns out other, than expected. In a certain degree these defects are eliminated in additive models of supply. We will consider influence on supply of a number of factors and, in particular, influence of the following major factors: goods price $(p)$, quality of goods $(g)$, price and quality of interchangeable goods $\left(p^{s}\right.$ и $\left.g^{s}\right)$, complementary goods $\left(p^{c}\right.$ и $\left.g^{c}\right)$, competitiveness of these goods $\left(k, k^{s}\right.$ и $\left.k^{c}\right)$, costs of production $\left(y_{T}\right)$, taxes and subsidies $\left(z_{T}\right)$, external conditions of production $\left(x_{T}\right)$ and expectations of producers $\left(e_{T}\right)$. 
For this purpose we will construct supply model equation:

$$
Q^{s}=Q_{1}^{s}+Q_{2}^{s}+\ldots+Q_{i}^{s}+\ldots+Q_{I}^{s},
$$

where $Q_{i}^{s}=Q_{i}^{s}\left(x_{i}\right)$ - function of the volume of supply on $i$-th factor, I - number of the factors influencing the supply of producers.

For the listed six factors in case of linearity of supply concerning each factor the additive supply is submitted in the form of:

$$
Q=a_{0}+a_{1} p-a_{2} g \pm a_{3} y \pm a_{4} z \pm a_{5} x \pm a_{6} e,
$$

Where $a_{0}$ - free coefficient of the equation which characterizes influence on supply of all other factors, except the considered factors $(p, g, \ldots, e)$. Other coefficients $a_{i}$ are defined as private derivative from supply on the corresponding $i$-th factor They can be determined, for example, by method of the smallest squares. Signs $(+)$ or (-) before coefficients depend on the direction of impact of each factor on supply volume.

In case of nonlinear dependence of each factorial supply $a_{i}$ on factor $x_{i}$ in the equation (4.3) nonlinear functions will be used taking into account the direction of influence of each factor on supply.

Let's consider the situation in the market presented in Table 1.

Table 1. Market situations and components of additive model of supply

\begin{tabular}{ccccccc}
\hline Factors & $\begin{array}{c}\text { Price } \\
(p)\end{array}$ & $\begin{array}{c}\text { Quality } \\
(g)\end{array}$ & $\begin{array}{c}\text { costs of } \\
\text { production }(y)\end{array}$ & $\begin{array}{c}\text { Subsidies } \\
(z)\end{array}$ & $\begin{array}{c}\text { External } \\
\text { conditions }(x)\end{array}$ & $\begin{array}{c}\text { Expectation of } \\
\text { producers }(e)\end{array}$ \\
\hline $\begin{array}{c}\text { Direction of influence } \\
\text { factor on supply }\end{array}$ & $\begin{array}{c}\text { Direct } \\
\text { Reverse }\end{array}$ & Reverse & Direct & Reverse & Reverse \\
Factor supply $Q_{i}$ & $\begin{array}{ccccc}Q_{1}(p) \\
a_{1} p\end{array}$ & $\begin{array}{c}Q_{2}(g) \\
a_{2} / g\end{array}$ & $\begin{array}{c}Q_{3}(y) \\
a_{3} / y\end{array}$ & $\begin{array}{c}Q_{4}(z) \\
a_{4} z\end{array}$ & $\begin{array}{c}Q_{5}(x) \\
a_{5} / x\end{array}$ & $\begin{array}{c}Q_{6}(e) \\
a_{6} / e\end{array}$ \\
\hline
\end{tabular}

According to this market situation we can determine the following consistent pattern: the volume of supply is in direct dependence on the price and subsidies, and inversely from quality of goods, costs of production, external conditions of production and expectation of producers of goods.

Thus the volume of supply is described by the following model:

$$
Q^{D}=a_{0}+a_{1} p+\frac{a_{2}}{g}+\frac{a_{3}}{y}+a_{4} z+\frac{a_{5}}{x}+\frac{a_{6}}{e}
$$

In case of use of any nonlinear functions factorial supplies have to be in direct dependence from the price of goods and subsidies, and function on quality of goods, costs of production of goods, external conditions of production and expectation of producers - inversely.

On the basis of the approach we stated and classification of market situations regarding the direction of influence of each factor on the supply we can restore the general additive model of the supply. Having analysed market situation, we allocate number of factors $\left(\kappa_{n p}\right)$, being in direct dependence and number of factors $\left(\kappa_{\text {обр }}\right)$, being in inverse relationship with supply volume. Then we can formulate supply in multidimensional space of factors as follows: supply volume increases in multidimensional space of factors with the growth of $\kappa_{n p}$ factors and decreases with the growth of $\kappa_{\text {oбp }}$.

Additive models of supply are convenient in primary analysis of supply from various factors, i.e. by consideration of supply from each factor, i.e. when studying a contribution of separately taken factor. Such models more specifically characterize diagrams the Marshall's curves of supply, and regarding shift of these curves.

If additive models are simpler models of supply, nonlinear (not additive) models of supply are represented much more promising as each factor is considered also in interrelation with all other factors of supply. Not additive model includes both additive part of model, and combinational factorial supplies of the first, second and higher orders. Thus the volume of supply is characterized by qualitatively new functional properties which aren't reduced to the sum of properties of its components Nonlinear Models of Supply.

Nonlinear models of supply are constructed as well as additive models of supply. Their synthesis in space of a number of factors assumes the accounting of the following economic situations in the market:

1. Factors of supply have to reflect market condition; 
2. Direction of influence of each factor on the supply of the producer;

3. Level of interrelation of factors, i.e. it is necessary to consider not only the directions of influence of each factor on the supply, but also their order of interaction.

Thus consideration of volume of supply joins interaction of supply of the first order (paired interaction of factors), interaction of supply of the second order (interaction of three factors) and interaction of supply of higher orders, for example, interaction $n$-th order (interaction of various combinations of $\mathrm{n}+1$ factors).

Factors and supply can have both direct, and inverse relationship therefore we suggest to introduce interrelations of a type $\left(x_{i} / x_{j}, x_{i} x_{j}\right)$ interaction of factors of the first order, $\left(x_{i} / x_{j} x_{k}, x_{i} x_{j} / x_{k}\right)$ - interaction of factors of the second order.

The factors making direct impact on supply register in numerators, and the factors which are with supply in inverse relationship settle down in denominators of the corresponding fractional sizes. Both in numerators, and in denominators there can be also more difficult functions from the considered factors.

Factors have to be quantitatively measured. If it is necessary to include the qualitative factor which doesn't have quantitative measurement in model, it needs to be given quantitative certainty. If factors $x_{i}$ and $x_{j}$ independent of each other, then there is no order of interaction for them. Thus, the structure of volume of supply in multidimensional space of factors includes all one-factorial volumes of supply and all combinational factorial supplies of the orders of the first, second, third, etc. interaction of factors.

The one-factorial volume of supply represents the supply volume depending on one factor. Their economic sense is that how each factor influences the volume of supply of the producer. The one-factorial volume of supply is described by function of one variable.

Combinational factorial supplies consist of volumes of supply of the first, second and higher orders of interaction determined respectively by interaction of two, three, etc. factors. The volume of supply of the first order of interaction is described by two-dimensional function, the second order of interaction by three-dimensional function, and the volume of supply of the $\mathrm{n}$-th order is described by $\mathrm{n}+1$-measured function.

Apparently, there is an optimal value of the order of interaction of supplies. In practice the volume of interaction of supply doesn't exceed the third order.

Taking into account the specified requirements and explanations to synthesis of model of supply the law of supply in multidimensional space of factors can be formulated as follows. The multidimensional volume of supply is equal to the algebraic sum of all one-factorial and all combinational factorial supplies. The direction of influence on supply of one-factorial and combinational factorial supplies is defined by the situations created in the market. Combinational factorial supplies make a share of supply and characterizes joint impact on a choice of the producer of several factors at the same time.

Supply volume in space of many factors is described by expression:

$$
Q^{s}=\sum_{i=1}^{I} Q_{i}^{s}+\sum_{i=1}^{I} \sum_{j=i+1}^{I} Q_{i j}^{s}+\sum_{i=1}^{I} \sum_{j=i+1}^{I} \sum_{k=j+1}^{I} Q_{i j k}^{s},
$$

where $Q_{i}^{s}=Q_{i}^{s}\left(x_{i}\right)-i$-th the one-factorial volume of supply, defined by $i$-th factor $x_{i} ; Q_{i j}^{s}=Q_{i j}^{s}\left(x_{i}, x_{j}\right)$ - the volume of supply of the first order caused by joint influence of $i$-th and $j$-th factors $x_{i}$ and $x_{i} ; Q_{i j k}^{s}=Q_{i j k}^{s}\left(x_{i}, x_{j}, x_{k}\right)^{-}$ volume of the factorial supply of the second order $i$-th, $j$-th and $\kappa$-th factors $x_{i}, x_{i}$ and $x_{k}$.

All factorial supplies of the first, second, third, etc. orders we called combinational factorial demands. We will note that one-factorial volumes of demand can be considered as combinational factorial demands of a zero order of inte action. Besides, the first sum in (6) represents additive model of supply.

The specific market situation, one-factorial and combinational factorial supplies is presented in Table 2, and also formed of six factors. Combinational components of factorial supplies are located above the diagonal elements formed of one-factorial supplies. The market situation is formed of six factors. The price, quality of goods and costs of production of goods make positive impact on demand. The subsidies, the current external conditions in the market of production and expectation of producers make the return impact on supply volume. 
Table 2. Market situation and components of the nonlinear model of supply

\begin{tabular}{|c|c|c|c|c|c|c|c|}
\hline & Factors & Price $(p)$ & $\begin{array}{c}\text { Quality } \\
(g)\end{array}$ & $\begin{array}{c}\text { Cost of } \\
\text { production }(y)\end{array}$ & $\begin{array}{c}\text { Subsidies } \\
(z)\end{array}$ & $\begin{array}{c}\text { External } \\
\text { conditions }(x)\end{array}$ & $\begin{array}{c}\text { Expectations of } \\
\text { producers }(e)\end{array}$ \\
\hline & $\begin{array}{l}\text { Direction of influence } \\
\text { factor on supply }\end{array}$ & Direct & Reverse & Reverse & Direct & Reverse & Reverse \\
\hline 1 & Price $(p)$ & $\begin{array}{c}Q_{l}(p) \\
a_{l} p\end{array}$ & $\begin{array}{l}Q_{12}(p, g) \\
a_{12} p / g\end{array}$ & $\begin{array}{c}Q_{13}(p, y) \\
a_{13} p / y\end{array}$ & $\begin{array}{l}Q_{14}(p, z) \\
a_{14} p z\end{array}$ & $\begin{array}{l}Q_{15}(p, x) \\
a_{15} p / x\end{array}$ & $\begin{array}{c}Q_{16}(p, e) \\
a_{16} p / e\end{array}$ \\
\hline 2 & Quality $(g)$ & & $\begin{array}{l}Q_{2}(g) \\
a_{2} / g\end{array}$ & $\begin{array}{l}Q_{23}(g, y) \\
a_{23} / g y\end{array}$ & $\begin{array}{l}Q_{24}(g, z) \\
a_{24} z / g\end{array}$ & $\begin{array}{l}Q_{25}(g, x) \\
a_{25} / g x\end{array}$ & $\begin{array}{c}Q_{26}(g, e) \\
a_{26} g e\end{array}$ \\
\hline 3 & Costs of production $(y)$ & & & $\begin{array}{c}Q_{3}(y) \\
a_{3} / y\end{array}$ & $\begin{array}{c}Q_{34}(y, z) \\
a_{34} z / y\end{array}$ & $\begin{array}{l}Q_{35}(y, x) \\
a_{35} / y x\end{array}$ & $\begin{array}{c}Q_{36}(y, e) \\
a_{36} / y e\end{array}$ \\
\hline 4 & Subsidies $(z)$ & & & & $\begin{array}{c}Q_{4}(z) \\
a_{4} z\end{array}$ & $\begin{array}{c}Q_{45}(z, x) \\
a_{45} z / x\end{array}$ & $\begin{array}{c}Q_{46}(z, e) \\
a_{46} / z e\end{array}$ \\
\hline 5 & External conditions $(x)$ & & & & & $\begin{array}{l}Q_{5}(x) \\
a_{5} / x\end{array}$ & $\begin{array}{c}Q_{56}(x, e) \\
a_{56} x e\end{array}$ \\
\hline 6 & Expectations of producers $(e)$ & & & & & & $\begin{array}{r}Q_{6}(e) \\
a_{6} / e\end{array}$ \\
\hline
\end{tabular}

\section{Conclusions}

Thus, the volume of supply of producers increases in process of growth of the price of goods and the size of subsidies, and also with reduction of requirements to quality, reduction of costs of production of goods, change of external conditions in favor of the producer, for example, the cost of materials and expectation decreased (for example, there was information on increase of the price of goods in the future).

\section{References}

Aghion, P., \& Tirole, J. (1997). Formal and real authority in organizations. Journal of Political Economy, 105(1), $1-29$.

Anderson, E. W., Fornell, C., Lehmann, D. R., \& Sullivan, M. W. (1993). The antecedents and consequences of customer satisfaction for firms. Marketing Science, 12(2), 125-143.

Bagautdunova, N. G., Safiullin, L. N., Safiullin, N. Z., \& Novenkova, A. Z. (2012). Theoretical aspects of public welfare rise. Proceedings 2nd Annual International Conference on Micro and Macro Economics (pp. 77-81). http://dx.doi.org/10.5176/2251-2055_MME1224

Bolton, R. N., \& Lemon, K. N. (1999). A dynamic model of customers' usage of services: Usage as an antecedent and consequence of satisfaction. Journal of Marketing Research, 36(2), 171-186.

Cadotte, E. R., Woodruff, R. B., \& Jenkins R. L. (1987). Expectations and norms in models of consumer satisfaction. Journal of Marketing Research, 24, 305-314.

Deming, W. E. (1982). Quality, Productivity, and Competitive Position. Cambridge, MA: MIT Press.

Gambu, M. (1988). Klaster analisys (p. 342).

Isikava, K. (1998). Japanese method of quality (p. 215).

Juran, J. M. (1992). Juran on Quality by Design: The New Steps for Planning Quality into Goods and Services. New York: The Free Press.

Laffont, J.-J. (1989). The Economics of Uncertainty and Information. The MIT Press, Cambridge, MA.

Laffont, J.-J., \& Martimort D. (2002). The Theory of Incentives: The Principal-Agent Model. Princeton University Press, Princeton, NJ.

Macho-Stadler, I., \& Pérez-Castrillo, J. D. (2001). An Introduction to the Economics of Information: Incentives and Contracts (2nd ed.). Oxford University Press, Oxford.

Morgan, N. A., \& Vorhies, D. W. (2001). Product quality alignment and business unit performance. Journal of Product Innovation Management, 18(6), 396-407. http://dx.doi.org/10.1016/S0737-6782(01)00112-6

Nelson, P. (1970). Information and consumer behavior. Journal of Political Economy, 78(2), 311-329.

Oliver, R. L. (2009). Satisfaction: A Behavioral Perspective on the Consumer. New York: M.E. Sharpe.

Porter, M. E. (1998). Competitive Advantage: Creating and Sustaining Superior Performance. New York, NY: 
The Free Press.

Quality Management Systems: Fundamentals and Vocabulary (3rd ed.). International Organization for Standardization, ISO 9000, ISO, Geneva.

Safiullin, L. N., Ismagilova, G. N., Safiullin, N. Z., \& Safiullin, M. R. (2012). Estimation of quality of the goods and satisfaction of consumers. Proceedings 2nd Annual International Conference on Micro and Macro Economics (pp. 61-63). http://dx.doi.org/10.5176/2251-2055_MME1223

\section{Copyrights}

Copyright for this article is retained by the author(s), with first publication rights granted to the journal.

This is an open-access article distributed under the terms and conditions of the Creative Commons Attribution license (http://creativecommons.org/licenses/by/3.0/). 